\title{
THE STRENGTH OF NICOTINE SOLUTIONS
}

\author{
By V. I. SAFro, Louisville, Ky.
}

The terms designating the strength of nicotine solutions are very often used quite loosely and in some cases erroneously. Too often, for instance, we see mentioned " 40 per cent nicotine sulphate" when the intent is to specify " 40 per cent nicotine as sulphate"-far from being an equivalent statement. It is highly desirable, then, that the factors that constitute the strength of nicotine solutions be well known and that certain old erroneous ideas be definitely disposed of. In order to bring this matter to the attention of entomologists, these nontechnical remarks are submitted.

When properly used as a spray, nicotine solutions are practically independent of sunlight, humidity, or any other atmospheric conditions for their effectiveness as contact insecticides, the problem in the field being concerned solely with wetting the insects thoroughly with a solution of the required nicotine strength. (The practice of using a greater nicotine strength is sometimes followed in order to make up for carelessness and lack of thoroughness on the part of the grower, or for the lack of spreading properties of the spray caused by using hard water without the addition of a sufficient softener and spreader.)

Odor No Indication of Comparative Strength.-Many growers make a practice of endeavoring to ascertain the comparative nicotine strength by the odor of the preparation. This has been a common practice among greenhouse men. As a matter of fact, the characteristic odor of tobacco is not due to nicotine. It is due to a great extent to the essential oils of the tobacco plant and to other extractive material with which we are at the present time not very well acquainted.

The writer has before him the following preparations:

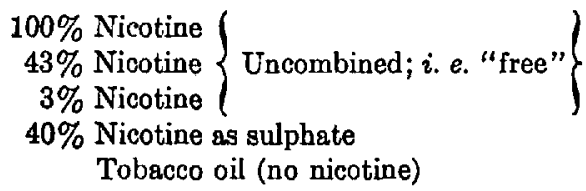

An attempt to obtain the comparative nicotine value of these preparations by odor is impossible. The preparation that contains the strongest tobacco odor is the preparation of tobacco oil which contains no nicotine whatever. On the other hand, the preparation containing 100 per cent "free" nicotine possesses very little odor and that differing quite materially from the tobacco oil. In fact, the odor present in the sample of 100 per cent "free" nicotine has no similarity to the characteristic tobacco odor. The preparation containing 3 per cent 
nicotine has a stronger odor than either the preparation containing. the 43 per cent or the 100 per cent, the 43 per cent having very little odor indeed. The preparation of 40 per cent nicotine as sulphate has a stronger odor than the preparation of 100 per cent "free" nicotine and is again of a different character than the odor of any of the other nicotine preparations.

Color No Indication of Comparative Strength.-We have been accustomed to believing that the higher nicotine concentration, the darker the color. The coloring matter is almost entirely due to materials other than the nicotine extracted from the tobacco plant. The preparations mentioned above in demonstrating that odor has no relation to nicotine strength may also be used to show that color is no indication of comparative nicotine content. The preparations containing 43 per cent and 100 per cent nicotine are almost the same in color-a transparent red-and both are clearer and lighter in color than the 40 per cent nicotine as sulphate and the nicotine-free tobacco oil, both of which are dark brown in color, almost opaque, and heavier than the other preparations.

Per Cent Nicotine Content Alone Insufficient as Statement of Exact Strength.-Most of the commercial nicotine solutions on the market contain 40 per cent nicotine by weight. The nicotine may be in the form of "free" nicotine or in the form of nicotine sulphate, but the per cent refers to the amount of nicotine, by weight, because it is the only method of knowing definitely how much actual nicotine is contained in the solution and such designation is required by the Federal Insecticide Board. It is necessary, then, to know the specific gravity of the preparation in order to know the actual nicotine content.

Below is a list of three commercial preparations, each containing 40 per cent nicotine by weight, showing the variations that exist in several preparations.

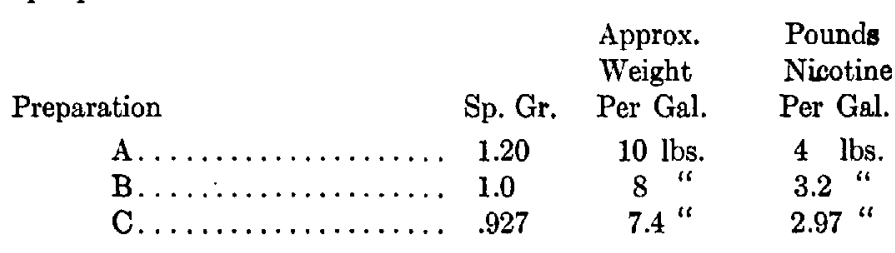

Dilutions, being by volume, would in the case of each of the above 40 per cent preparations give solutions of widely different nicotinecontent, granting that the same dilution is used with each preparation.

Per Cent Nicotine Content together with Specific Gravity Constitutes Statement of Exact Strength and Comparative VALUE.-In order to know the definite value of a nicotine solution, 
the total weight of nicotine in the solution should be known. In the three commercial preparations mentioned above, each preparation is labelled 40 per cent nicotine and yet in one case four pounds of nicotine and in another only 2.97 pounds of nicotine are contained in the same volume of solution.

\section{Scientific Notes}

European Elm Scale. On May 27th, the writer found an American elm on the college grounds infested with European elm scale (Gossyparia spuria). This, apparently, is the first time the insect has made its appearance at Ames. The college collection has a specimen from Des Moines, but we have been unable to find a published record for this state.

Albert Hartzell, Ames, Iowa.

European Corn Borer (Pyrausta nubilalis Hubn.) in New York. A recent determination by Messrs. Heinrich and Schaus, through the courtesy of Doctor L. O. Howard, of moths reared from corn stalks collected near Schenectady has positively established the occurrence of this serious pest in New York State. A subsequent identification by Mr. Heinrich of moths reared from corn boring larvæ suspected of being Pyrausia nubilalis has shown the Dutchess County insect to be Pyrausta penitalis Grote. This is welcome news and unless upset by subsequent discoveries, means that European corn borers occur in but one area in New York State and probably in but two in the United States.

E. P. Felt.

Corn Borer in Connecticut not the European Species. In this Journal for April, page 218 , is a note to the effect that "what appears to be a small infestation of the European corn borer was found in Milford, Conn., March 12." Adults have now been reared from this material and we are pleased to announce that they have been identified by specialists at Washington as Pyrausta penilalis Grote, and not the European corn borer, Pyrausta nubilalis Hubner. W. E. Britton.

Swarms of Aphids. On June 23 and 24 vehicles and pedestrians passing through Chapel Street, and some other nearby thoroughfares in New Haven, Conn., were literally covered with small green insects which were flying in the air and were caught on the clothes, and tops of automobiles. One of the seed stores telephoned to my office inquiring what they were; some of their customers took them to be the arrival of the much heralded "seventeen year locust." On investigating the matter they were found to be aphids, afterwards identified by Dr. Edith M. Patch as Calaphis betuloscolens Fitch, a species infesting birch and supposed to remain upon that host throughout the season. Just why they migrated is a conundrum, unless because they became 50 abundant that they were forced to leave in search of food. Though there are a few birches in the city, there are doubtless many acres on the Orange hills, two or three miles to the southwest, from whence they came. Several observers noticed the swarms of aphids in New Haven and Hamden at this time and also the preceding week.

W. E. BritTon.

Army Entomological Laboratory. Malcolm E. MacGregor, a Carnegie student who studied in this country several years ago, informed Dr. Howard in a recent letter that he is in charge of the War Office Entomological Laboratory, Kitchener Camp, Sandwich, Kent, adding that the tropical campaigns have made the English tumble on many facts which they could not see before. The laboratory exemplifies the last word in modernity, all the apparatus being run by electricity and the equipment being beautiful in every way. Mr. MacGregor extends a most hearty welcome to any American entomologist who may be visiting in England.

E. P. F. 